\title{
VALIDITY AND RELIABILITY OF THE ACCEPTANCE AND ACTION QUESTIONNAIRE-II: LATVIAN VERSION
}

\author{
Inese Sadauska, Aleksandrs Koḷesovs \\ University of Latvia, Latvia
}

\begin{abstract}
The objective of this study was to assess the psychometric properties of the Latvian version of the Acceptance and Action Questionnaire-II (AAQ-II), measuring psychological flexibility described as the ability to act according to chosen values while consciously being in contact with subjectively unpleasant present moment experiences. The scale provides a single score across 7 items. The original AAQ-II was translated to Latvian and then back to English. The Satisfaction with Life Scale, Flourishing Scale and Meaning in Life Questionnaire was applied for testing the convergent validity of the AAQ-II. Participants of the study were 191 people, ranged in age from 19 to 68 ( 159 women, mean age $M=30.62, S D=9.50$ ). Reliability analysis, exploratory and confirmatory factor analysis (EFA and CFA) of the scale were performed. EFA indicated a one-factor structure. Results showed that the Latvian version of AAQ-II has good psychometric properties and convergent validity. Testing of the original model by CFA resulted in acceptable fit indices.
\end{abstract}

Keywords: Acceptance and Action Questionnaire II (AAQ-II), experiential avoidance, psychological flexibility.

\section{Introduction}

Interest in psychological flexibility (PF) has been growing in the last decade, given the increasing evidence linking mental health status and well-being to the way how people relate to their psychological experiences. PF is defined as "the ability to fully contact the present moment and the thoughts and feelings it contains without needless defense, and, depending upon what the situation affords, persisting in or changing behavior in the pursuit of values and goals" (Hayes et al., 2006, p. 6). The opposite to psychological flexibility is psychological inflexibility. Psychological inflexibility is characterized by a behavioral pattern of excessive control of a person's thoughts, feelings, and emotions, with a tendency to avoid unpleasant internal experiences at the expense of more effective or valued actions (Levin et al., 
2014). Renshaw (2018) posits, that psychological wellbeing is supported and maintained by psychologically flexible behavior, whereas the development of mental health difficulties is facilitated by psychologically inflexible behavior. When certain types or levels of private experiences are avoided whether they are our inner thoughts or feelings or external situations, we can talk about psychological rigidity or inflexibility that is a central component in the development and maintaining of psychopathology, which limits emotional well-being and diminishes the quality of life.

The concept of psychological flexibility has received the most attention within the model of human functioning on which the Acceptance and Commitment Therapy is based (ACT, Hayes et al., 1999). The third-wave cognitive behavioral therapy approach, ACT promotes PF that entails the person's ability to contact the present moment more fully, including the problematic private experiences which involve persisting in or changing behavior in pursuit of personal values and goals instead of engaging in experiential avoidance (EA) (Hayes et al., 2006). The ACT model states that the following six interdependent processes contribute to PF: (a) acceptance, (b) cognitive defusion, (c) contact with the present moment or mindfulness, (d) self-as-context, (e) values, and (f) committed action (see Hayes et al., 2012, for details).

EA refers to a process by which humans work to avoid, alter, or suppress difficult private experiences and can thus be understood as an example of psychological inflexibility. Research shows that EA is associated with anxiety, depression, and stress symptom severity, eating disorders, and a ariety of chronic physical health conditions, such as chronic pain, as well as worse social functioning, lower mindfulness, and self-compassion (Levin et al., 2014; Shorey et al., 2017; Spinhoven et al., 2014; Edwards \& Vowles, 2020; Fledderus et al., 2012; Monestès et al., 2018; Pennatoe et al., 2013; Zhang et al., 2014; Bardeen \& Fergus, 2016). It has been demonstrated that experiential avoidance explains the poorer quality of life among non-clinical samples (Kashdan et al., 2006). These findings suggest that psychological inflexibly may be a transdiagnostic process that is associated with higher risks of many forms of psychopathology.

The most widely used instrument to measure psychological inflexibility as represented by its overarching process of experiential avoidance is the Acceptance and Action Questionnaire (AAQ; Hayes et al., 2004) originally developed as 9 item scale and later modified to a 7-item self-reported measure (Bond et al., 2011). Although AAQ is generically referenced to as a measure of experiential avoidance, it is a more general measure of several processes affecting the PF such as fusion with thoughts, avoidance of feelings, inability to act in the presence of difficult private events (Hayes et al., 2006). 
AAQ-II has been criticized regarding whether it measures psychological inflexibility and whether it discriminates between psychological inflexibility as a process, such as an attitude towards one's feelings and thoughts, and the supposed outcomes, such as the emotional problems (Rochefort et al., 2018; Tyndall et al., 2019; Chawla \& Ostafin, 2007; Wolgast, 2014). As a result, many other instruments assessing PF or variants of it have been or are under development, including Open Engaged State Questionnaire (Benoy et al., 2019), Comprehensive Assessment of Acceptance and Commitment Therapy (Francis et al., 2016), Personalized Psychological Flexibility Index (PPFI; Kashdan et al., 2020) and Multidimensional Experiential Avoidance Questionnaire (Gámez et al., 2011). However, AAQ-II still remains the most widely used measure of PF and it has been demonstrated that the AAQ-II explains additional variance above established measures of symptomatology (e. g., Gloster et al., 2011) and scores on AAQ-II seem to be stable across time, despite fluctuations in current emotional disorder (e. g., Spinhoven et al., 2014, 2016). Since PF can be contextually controlled and while a person can function well in most situations, he or she can show inflexibility in one specific situation, various variations of the AAQ have been developed to address disorder-specific content such as tinnitus (Westin et al., 2008), chronic pain (Vowles et al., 2008), psychosis (Shawyer et al., 2007), smoking dependence (Gifford et al., 2004), weight-related problems (Lillis \& Hayes, 2008) and others.

The AAQ-II has been translated to and validated in several languages (Chang et al., 2017; Karekla \& Michaelides, 2017; Pennato et al., 2013; Zhang et al., 2014; Costa et al., 2014; Cheng et al., 2017; Eisenbeck \& Szabó-Bartha, 2018; Østergaard et al., 2020), supporting the validity and unifactorial model of the instrument. The present study focuses on analyzing the psychometric properties of the Latvian version of the AAQ-II, testing its validity, reliability, and factor structure, thus adapting a new measure of psychological well-being into the Latvian language.

\section{Method}

\section{Participants}

A total of 191 adults ( $83 \%$ female, aged from 19 to 68 years, $M=30.62$, $S D=9.50$ ) participated in the study. The snowball convenience sample involved psychology students (52\%) and their friends or relatives, 63\% were employed, $56 \%$ were either married or in a relationship.

\section{Measures}

The Acceptance and Action Questionnaire II (AAQ-II, Bond et al., 2011) includes seven items rated on a Likert scale $(1=$ never true; $7=$ always 
true), with higher totals, as scored in our study, indicated less psychological flexibility. The AAQ-II has been found to have good internal consistency with alpha coefficients ranging from .78 to .88 , and satisfactory test-retest reliability at 3 (.81) and 12-months (.79) (Bond et al., 2011).

The Flourishing Scale (FS; Diener et al., 2010) is a 7-point Likert scale with 8 items (from strong disagreement to strong agreement) that measures participant's beliefs about such areas of their life as positive relationships, meaning, and purpose in life, as well as a sense of competence. Scores can range from 8 to 56 (demonstrating strong agreement on all scales). The adaptation of the scale in Latvian by Sadauska and Kolesovs (2021) was used. In the current study, the Cronbach's alpha of the FS was .88.

The Satisfaction with Life Scale (SWLS; Diener et al., 1985) with five items assess the cognitive evaluation of life as desirable on a 7-point Likert scale with responses varying from strong disagreement to strong agreement. The adaptation of the scale in Latvian by Upmane (2012) was used. In the current study, the Cronbach's alpha of the SWLS was .87.

Meaning in Life Questionnaire (MLQ; Steger, Frazier, Oishi, \& Kaler, 2006) is the ten-item scale measuring the presence and search for meaning and purpose in life. Only the 5-item presence subscale (MLQ-P) was used. Items are rated 7-point Likert scale with responses varying from strong disagreement to strong agreement. The adaptation in Latvian demonstrated good internal consistency of the subscale (Kolesovs, 2019). In the current study, the Cronbach's alpha of the MLQ-P was .91.

Self-reported health status was assessed by a single item measurement of participant's self-assessment of physical health in comparison with other people of the same age on a 5-point scale from very poor to very good.

Self-reported economic well-being was assessed by a single item measurement of participant's self-assessment of their family's economic well-being on a 5-point scale from "missing even the most basic things" to "can afford anything I want".

\section{Procedure}

The AAQ-II translation procedure consisted of two steps. Firstly, the English version of the questionnaire was simultaneously translated into Latvian by independent translators. Secondly, the resulting Latvian version was back-translated and compared to the original English version.

All participants were informed of the aim of the study, personal anonymity, and the confidentiality of the survey. Data collection occurred in the winter of 2019.

Analyses of the data obtained were performed using the lavaan $\mathrm{R}$ package Version i386 3.5.2 and IBM SPSS Statistics Version 22.0. 


\section{Results}

The data were analyzed in three steps: the exploratory factor analyses (EFA), the confirmatory factor analyses (CFA), and convergent validity analyses which included the testing relationship of the AAQ-II with well-being measures.

\section{Exploratory factor analysis}

The exploratory factor analysis (EFA) was performed applying principal component analyses extraction with Varimax rotation. Before performing EFA, the suitability of data for factor analysis was assessed. The Kaiser Meyer-Olkin value was .88, demonstrating a good level of sampling adequacy. Bartlett's Test of Sphericity reached statistical significance, confirming that data were factorable, $\chi^{2}(21)=754.35, p<.001$. The principal components analysis revealed the presence of one factor with an eigenvalue above 1 (4.34), accounting for $63 \%$ of the variance. The factor loading ranged from .83 to .77 . Therefore, only one factor characterized the AAQ-II (Table 1).

Table 1. Exploratory Factor Analysis of AAQ-II

\begin{tabular}{|l|l|l|}
\hline \multicolumn{2}{|l|}{ Factor structure } \\
\hline AAQ-II item & Loading & $\mathbf{h}^{2}$ \\
\hline $\begin{array}{l}\text { A1 My painful experiences and memories make it difficult for me } \\
\text { to live a life that I would value. }\end{array}$ & .77 & .59 \\
\hline A2 I'm afraid of my feelings. & .83 & .68 \\
\hline $\begin{array}{l}\text { A3 I worry about not being able to control my worries and } \\
\text { feelings. }\end{array}$ & .82 & .67 \\
\hline A4 My painful memories prevent me from having a fulfilling life. & .83 & .69 \\
\hline A5 Emotions cause problems in my life. & .78 & .61 \\
\hline $\begin{array}{l}\text { A6 It seems like most people are handling their lives better than } \\
\text { I am. }\end{array}$ & .77 & .59 \\
\hline A7 Worries get in the way of my success. & .78 & .60 \\
\hline Factor and scale characteristics & Value \\
\hline Kaiser Meyer-Olkin & .88 \\
\hline Bartlett's Test of Sphericity, $\chi^{2}(21)$ & $754,35, p<.001$ \\
\hline Eigenvalue & 4.43 \\
\hline Explained Variance & $63 \%$ \\
\hline Cronbach's Alpha & .90 \\
\hline$M(S D)$ & $22.82(10.49)$ \\
\hline & & \\
\hline
\end{tabular}




\section{Confirmatory factor analysis}

A seven-item, one-factor model, as identified by EFA was investigated. The initial model showed low level of fit to data $\chi^{2}(14)=54.551$, $p<.001$. The original model's CFI $=.92$ and TLI $=.88$ indicated acceptable fit, but the RMSEA of .12 failed to reach the recommended values between .05 and .08, indicating a not well-fitted model. Given the high RMSEA value, the model was statistically modified by correlating errors between Item 1 and Item 4 (see Fig.1).

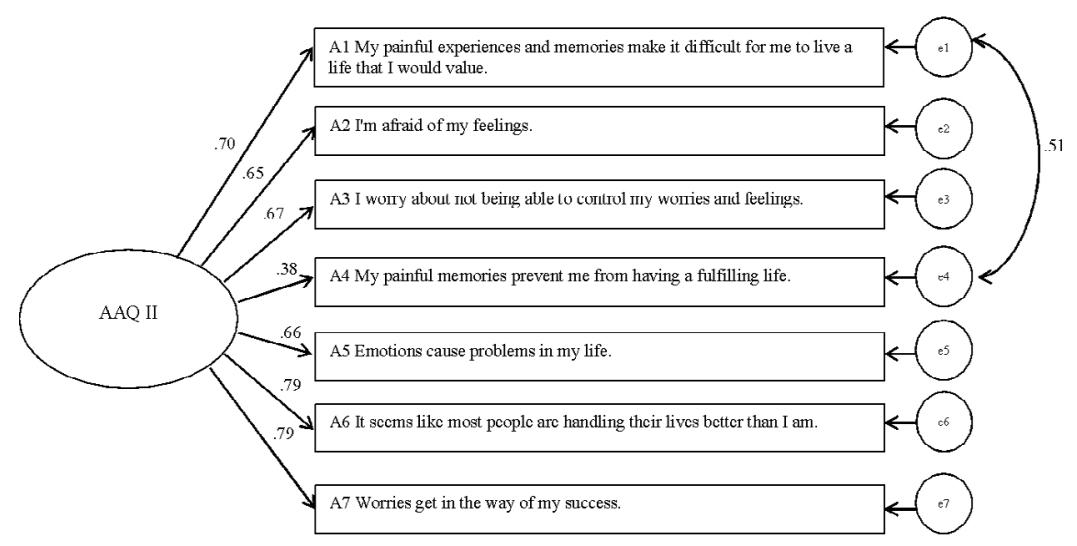

Figure 1. One factor confirmatory model of AAQ-II

This correction has been used in a number of previous studies (Gloster et al., 2011; Karekla \& Michaelides, 2017; Eisenbeck \& Szabó-Bartha, 2018) and appears in the AAQ-II baseline model created for European culture (Monestès et al., 2018). These error terms can be explained by the overlapping content between the items mentioned. The modification resulted in a better fit, with CFI $=.99$, TLI $=.98$, and RMSEA $=.06$, indicating satisfactory fit. These analyses confirm the unidimensional factor structure of the FS. Fit statistics for both models are reported in Table 2.

Table 2. Goodness of fit statistics for the tests of factorial validity of the AAQ-II

\begin{tabular}{|l|l|l|l|l|l|l|}
\hline & $\chi^{2}$ & df & CFI & TLI & SRMR & $\begin{array}{l}\text { RMSEA } \\
(\mathbf{9 0 \%} \text { CI) }\end{array}$ \\
\hline Model 1 & 54.551 & 14 & .939 & .908 & .050 & .123 \\
\hline Model 2 & 23.158 & 13 & .985 & .975 & .031 & .064 \\
\hline
\end{tabular}

Model 1 - original model; model 2 - Errors of Items 1 and 4's covary. 


\section{Testing convergent validity}

To investigate the convergent validity of the AAQ-II, we correlated SWLS, FS and MLQ-P, single-item health status and economic well-being questions with AAQ-II (see Table 3). There were strong, negative correlations between the AAQ-II, FS and life satisfaction, as well as the presence of meaning and purpose in life. AAQ-II was also negatively, significantly associated with health, and economic well-being. These results are consistent with published reports on AAQ-II (e. g., Eisenbeck \& Szabó-Bartha, 2018; Karekla \& Panayioutou, 2011; Kashdan et al., 2006, 2020).

Table 3. Pearson correlations between the AAQ-II, FS, SWLS, MLQ-P, health and economic well-being

\begin{tabular}{|l|l|l|l|l|l|}
\hline Measures & 1 & 2 & 3 & 4 & 5 \\
\hline $\begin{array}{l}\text { 1. Acceptance and Action Questionnaire } \\
\text { (AAQ-II) }\end{array}$ & - & & & & \\
\hline 2. Satisfaction with Life Scale (SWLS) & $-.55^{* *}$ & - & & & \\
\hline 3. Florishing Scale (FS) & $-.68^{* *}$ & $.70^{* *}$ & - & & \\
\hline $\begin{array}{l}\text { 4. Meaning in Life Questionnaire - Presence } \\
\text { of meaning scale (MLQ-P) }\end{array}$ & $-.68^{* *}$ & $.56^{* *}$ & $.71^{* *}$ & - & \\
\hline 5. Health & $-.31^{* *}$ & $.37^{* *}$ & $.39^{* *}$ & $.19^{*}$ & - \\
\hline 6. Economic well-being & $-.24^{* *}$ & $.40^{* *}$ & $.28^{* *}$ & $.22^{* *}$ & $.29^{* * *}$ \\
\hline
\end{tabular}

${ }^{*} p<.05 .{ }^{* *} p<.01$

\section{Discussion}

The overall purpose of this study was to evaluate the psychometric properties of the AAQ-II Latvian version. The results suggest that the AAQ-II displays sufficient psychometric properties to be further used by clinicians and researchers with Latvian participants.

The CFA suggested a one-factor solution similar to findings from other psychometric studies of the AAQ-II (e. g., Bond et al., 2011; Lundgren \& Parling, 2017; Østergaard et al., 2020, Edwards \& Vowles, 2020), after accounting for correlated measurement errors explainable by method effects in items 1 and 4. Items 1 and 4 both refer to, "my painful memories". The modified model fit the data well and supported the one-factor solution also found in administering the AAQ-II in additional languages other than English (e. g., Eisenbeck \& Szabó-Bartha, 2018; Lundgren \& Parling, 2017; Ruiz et al., 2016).

Psychological flexibility is a promising psychological process to assess and target for improving mental health and psychological well-being. Recent publications on psychological flexibility acknowledge the difficulties 
and confusion in measuring the construct of PF (e. g., Doorley et al., 2020). Even though AAQ-II is referred to as measuring PF, it really measures its opposite, i. e., experiential avoidance or psychological inflexibility, inferring the existence of PF by the mere absence of EA. Meanwhile, the construct of psychological flexibility as defined in the context of Acceptance and Commitment Therapy, includes more dimensions than just experiential avoidance. Currently, several promising measures are developed to capture the PF (e. g., PPFI, Kashdan et al., 2020; MPFI, Rolffs et al., 2019; CompACT, Francis et al., 2016).

This study acknowledges several limitations. First, our sample was limited to a convenience sample of predominantly students (52\%), with the mean age of 30,62 and the majority of them female (83\%). Therefore, broader samples, representative of the adult population could be studied in the future. The psychometric properties of AAQ-II should be examined further in a clinical sample. Furthermore, test-retest reliability of the Latvian version should be evaluated.

Overall, the present version of the AAQ-II is reliable and suitable for researchers and practitioners planning to study new aspects of well-being in a Latvian cultural context. The AAQ-II can also be used by clinicians for assessing the outcomes of interventions directed at lowering experiential avoidance.

\section{Conclusions}

This study evaluated the psychometric properties of AAQ-II Latvian version. Factor analysis suggested a unidimensional model of PF, which was consistent with the results in other linguistic samples. The findings support the reliability and validity of the instrument.

The overall results add further support to the process of psychological flexibility as a precursor to well-being, flourishing, and presence of meaning in life. Further studies are needed to confirm the findings in diverse clinical and non-clinical samples.

\section{References}

Bardeen, J. R., \& Fergus, T. A. (2016). The interactive effect of cognitive fusion and experiential avoidance on anxiety, depression, stress and posttraumatic stress symptoms. Journal of Contextual Behavioral Science, 5(1), 1-6. https://doi.org/10.1016/ j.jcbs.2016.02.002

Benoy, C., Knitter, B., Knellwolf, L., Doering, S., Klotsche, J., \& Gloster, A. T. (2019). Assessing psychological flexibility: Validation of the Open and Engaged State Questionnaire. Journal of Contextual Behavioral Science, 12, 253-260. https://doi.org/10.1016/ j.jcbs.2018.08.005 
Bond, F. W., \& Bunce, D. (2003). The Role of Acceptance and Job Control in Mental Health, Job Satisfaction, and Work Performance. Journal of Applied Psychology, 88(6), 1057-1067. https://doi.org/10.1037/0021-9010.88.6.1057

Bond, F. W., Hayes, S. C., Baer, R. A., Carpenter, K. M., Guenole, N., Orcutt, H. K., Waltz, T., \& Zettle, R. D. (2011). Preliminary Psychometric Properties of the Acceptance and Action Questionnaire-II: A Revised Measure of Psychological Inflexibility and Experiential Avoidance. Behavior Therapy, 42(4), 676-688. https://doi.org/10.1016/j. beth.2011.03.007

Chang, W. H., Chi, L., Lin, S.-H., \& Ye, Y.-C. (2017). Psychometric Properties of the Acceptance and Action Questionnaire - II for Taiwanese College Students and Elite Athletes. Current Psychology, 36(1), 147-156. https://doi.org/10.1007/s12144-0159395-x

Chawla, N., \& Ostafin, B. (2007). Experiential avoidance as a functional dimensional approach to psychopathology: An empirical review. Journal of Clinical Psychology, 63(9), 871-890. https://doi.org/10.1002/jclp.20400

Costa, J., Marôco, J., Pinto-Gouveia, J., \& Galhardo, A. (2014). Validation of the Psychometric Properties of Acceptance and Action Questionnaire-II in Clinical and Nonclinical Groups of Portuguese Population. International Journal of Psychology, 12.

Diener, E., Emmons, R. A., Larsen, R. J., \& Griffin, S. (1985). The Satisfaction With Life Scale. Journal of Personality Assessment, 49(1), 71. https://doi.org/10.1207/ s15327752jpa4901_13

Diener, E., Wirtz, D., Tov, W., Kim-Prieto, C., Choi, D., Oishi, S., \& Biswas-Diener, R. (2010). New well-being measures: short scales to assess flourishing and positive and negative feelings. Social Indicators Research, 97(2), 143-156. https://doi.org/10.1007/ s11205-009-9493-y

Doorley, J. D., Goodman, F. R., Kelso, K. C., \& Kashdan, T. B. (2020). Psychological flexibility: What we know, what we do not know, and what we think we know. Social and Personality Psychology Compass, 14(12), e12566. https://doi.org/10.1111/spc3.12566

Edwards, K. A., \& Vowles, K. E. (2020). Acceptance and Action Questionnaire - II: Confirmatory factor analysis and measurement invariance between Non-Hispanic White and Hispanic/Latinx undergraduates. Journal of Contextual Behavioral Science, 17, 32-38. https://doi.org/10.1016/j.jcbs.2020.05.003

Fledderus, M., Oude Voshaar, M. A. H., Ten Klooster, P. M., \& Bohlmeijer, E. T. (2012). Further evaluation of the psychometric properties of the Acceptance and Action Questionnaire-II. Psychological Assessment, 24(4), 925-936. https://doi.org/10.1037/ a0028200

Francis, A. W., Dawson, D. L., \& Golijani-Moghaddam, N. (2016). The development and validation of the Comprehensive assessment of Acceptance and Commitment Therapy processes (CompACT). Journal of Contextual Behavioral Science, 5(3), 134-145. https:// doi.org/10.1016/j.jcbs.2016.05.003

Gámez, W., Chmielewski, M., Kotov, R., Ruggero, C., \& Watson, D. (2011). Development of a measure of experiential avoidance: The Multidimensional Experiential Avoidance Questionnaire. Psychological Assessment, 23(3), 692-713. https://doi.org/10.1037/ a0023242

Gifford, E. V., Kohlenberg, B. S., Hayes, S. C., Antonuccio, D. O., Piasecki, M. M., Rasmussen-Hall, M. L., \& Palm, K. M. (2004). Acceptance-based treatment for smoking cessation. Behavior Therapy, 35(4), 689-705. https://doi.org/10.1016/S00057894(04)80015-7 
Gloster, A. T., Klotsche, J., Chaker, S., Hummel, K. V., \& Hoyer, J. (2011). Assessing psychological flexibility: What does it add above and beyond existing constructs? Psychological Assessment, 23(4), 970-982. https://doi.org/10.1037/a0024135

Hayes, S. C. (2016). Acceptance and Commitment Therapy, Relational Frame Theory, and the Third Wave of Behavioral and Cognitive Therapies - Republished Article. Behavior Therapy, 47(6), 869-885. https://doi.org/10.1016/j.beth.2016.11.006

Hayes, S. C., Luoma, J. B., Bond, F. W., Masuda, A., \& Lillis, J. (2006). Acceptance and Commitment Therapy: Model, processes and outcomes. Behaviour Research and Therapy, 44(1), 1-25. https://doi.org/10.1016/j.brat.2005.06.006

Hayes, S. C., Strosahl, K. D., \& Wilson, K. G. (1999). Acceptance and commitment therapy: An experiential approach to behavior change. New York, NY: Guilford Press.

Hayes, S. C., Strosahl, K. D., \& Wilson, K. G. (2012). Acceptance and commitment therapy: The process and practice of mindful change ( $2^{\text {nd }}$ ed.). New York, NY: Guilford Press.

Hayes, S. C., Strosahl, K., Wilson, K. G., Bissett, R. T., Pistorello, J., Toarmino, D., Polusny, M. A., Dykstra, T. A., Batten, S. V., Bergan, J., Stewart, S. H., Zvolensky, M. J., Eifert, G. H., Bond, F. W., Forsyth, J. P., Karekla, M., \& McCurry, S. M. (2004). Measuring Experiential Avoidance: A Preliminary Test of a Working Model. Psychological Record, 54(4), 553. https://doi.org/10.1007/BF03395492

Karekla, M., \& Michaelides, M. P. (2017). Validation and invariance testing of the Greek adaptation of the Acceptance and Action Questionnaire -II across clinical vs. Nonclinical samples and sexes. Journal of Contextual Behavioral Science, 6(1), 119-124. https://doi. org/10.1016/j.jcbs.2016.11.006

Karekla, M., \& Panayiotou, G. (2011). Coping and experiential avoidance: Unique or overlapping constructs? Journal of Behavior Therapy and Experimental Psychiatry, 42(2), 163-170. https://doi.org/10.1016/j.jbtep.2010.10.002

Kashdan, T. B., Barrios, V., Forsyth, J. P., \& Steger, M. F. (2006). Experiential avoidance as a generalized psychological vulnerability: Comparisons with coping and emotion regulation strategies. Behaviour Research and Therapy, 44(9), 1301-1320. https://doi. org/10.1016/j.brat.2005.10.003

Kashdan, T. B., Disabato, D. J., Goodman, F. R., Doorley, J. D., \& McKnight, P. E. (2020). Understanding psychological flexibility: A multimethod exploration of pursuing valued goals despite the presence of distress. Psychological Assessment, 32(9), 829-850. https://doi.org/10.1037/pas0000834

Kashdan, T. B., \& Rottenberg, J. (2010). Psychological flexibility as a fundamental aspect of health. Clinical Psychology Review, 30(7), 865-878. https://doi.org/10.1016/j. cpr.2010.03.001

Kolesovs, A. (2019). Adaptation of the Meaning in Life Questionnaire in Latvian. Sociālo Zinātñu Vēstnesis, 1(28), 109-120.

Levin, M. E., MacLane, C., Daflos, S., Seeley, J., Hayes, S. C., Biglan, A., \& Pistorello, J. (2014). Examining psychological inflexibility as a transdiagnostic process across psychological disorders. Journal of Contextual Behavioral Science, 3(3), 155-163. https:// doi.org/10.1016/j.jcbs.2014.06.003

Lillis, J., \& Hayes, S. C. (2007). Measuring avoidance and inflexibility in weight related problems. International Journal of Behavioral Consultation and Therapy, 4(1), 30-40. http://dx.doi.org/10.1037/h0100829

Lundgren, T., \& Parling, T. (2017). Swedish Acceptance and Action Questionnaire (SAAQ): A psychometric evaluation. Cognitive Behaviour Therapy, 46(4), 315-326. https://doi.org/ 10.1080/16506073.2016.1250228 
Monestès, J.-L., Karekla, M., Jacobs, N., Michaelides, M. P., Hooper, N., Kleen, M., Ruiz, F. J., Miselli, G., Presti, G., Luciano, C., Villatte, M., Bond, F. W., Kishita, N., \& Hayes, S. C. (2018). Experiential avoidance as a common psychological process in European cultures. European Journal of Psychological Assessment, 34(4), 247-257. https://doi. org/10.1027/1015-5759/a000327

Østergaard, T., Lundgren, T., Zettle, R. D., Landrø, N. I., \& Haaland, V. Ø. (2020). Norwegian Acceptance and Action Questionnaire (NAAQ): A psychometric evaluation. Journal of Contextual Behavioral Science, 15, 103-109. https://doi.org/10.1016/j. jcbs.2019.12.002

Pennato, T., Berrocal, C., Bernini, O., \& Rivas, T. (2013). Italian Version of the Acceptance and Action Questionnaire-II (AAQ-II): Dimensionality, Reliability, Convergent and Criterion Validity. Journal of Psychopathology and Behavioral Assessment, 35(4), 552-563.

Renshaw, T. L. (2018). Probing the relative psychometric validity of three measures of psychological inflexibility. Journal of Contextual Behavioral Science, 7, 47-54. https:// doi.org/10.1016/j.jcbs.2017.12.001

Rochefort, C., Baldwin, A. S., \& Chmielewski, M. (2018). Experiential Avoidance: An Examination of the Construct Validity of the AAQ-II and MEAQ. Behavior Therapy, 49(3), 435-449. https://doi.org/10.1016/j.beth.2017.08.008

Rolffs, J. L., Rogge, R. D., \& Wilson, K. G. (2018). Disentangling Components of Flexibility via the Hexaflex Model: Development and Validation of the Multidimensional Psychological Flexibility Inventory (MPFI). Assessment, 25(4), 458-482. https://doi. org/10.1177/1073191116645905

Ruiz, F. J., Flórez, C. L., García-Martín, M. B., Monroy-Cifuentes, A., Barreto-Montero, K., García-Beltrán, D. M., Riaño-Hernández, D., Sierra, M. A., Suárez-Falcón, J. C., Cardona-Betancourt, V., \& Gil-Luciano, B. (2018). A multiple-baseline evaluation of a brief acceptance and commitment therapy protocol focused on repetitive negative thinking for moderate emotional disorders. Journal of Contextual Behavioral Science, 9, 1-14. https://doi.org/10.1016/j.jcbs.2018.04.004

Sadauska, I., \& Kol̦esovs, A. (2021). Validity and reliability of the Flourishing Scale: Latvian version. Society. Integration. Education. Proceedings of the International Scientific Conference. Volume VII, May $28^{\text {th }}-29^{\text {th }}, 2021$. 171-180. https://dor.org/ 10.17770/ sie2021vol7.6402

Shawyer, F., Ratcliff, K., Mackinnon, A., Farhall, J., Hayes, S., \& Copolov, D. (2007). The voices acceptance and Action Scale (VAAS): Pilot data. Journal of Clinical Psychology, 63, 593-606. https://doi.org/10.1002/jclp.20366

Shorey, R. C., Gawrysiak, M. J., Elmquist, J., Brem, M., Anderson, S., \& Stuart, G. L. (2017). Experiential avoidance, distress tolerance, and substance use cravings among adults in residential treatment for substance use disorders. Journal of Addictive Diseases, 36(3), 151-157. https://doi.org/10.1080/10550887.2017.1302661

Spinhoven, P., Drost, J., de Rooij, M., van Hemert, A. M., \& Penninx, B. W. (2014). A ongitudinal Study of Experiential Avoidance in Emotional Disorders. Behavior Therapy, 45(6), 840-850. https://doi.org/10.1016/j.beth.2014.07.001

Spinhoven, P., Drost, J., de Rooij, M., van Hemert, A. M., \& Penninx, B. W. J. H. (2016). Is Experiential Avoidance a Mediating, Moderating, Independent, Overlapping, or Proxy Risk Factor in the Onset, Relapse and Maintenance of Depressive Disorders? Cognitive Therapy and Research, 40(2), 150-163. https://doi.org/10.1007/s10608-015-9747-8

Steger, M. F., Frazier, P., Oishi, S., \& Kaler, M. (2006). The meaning in life questionnaire: Assessing the presence of and search for meaning in life. Journal of Counseling Psychology, 53(1), 80-93. https://doi.org/10.1037/0022-0167.53.1.80 
Tyndall, I., Waldeck, D., Pancani, L., Whelan, R., Roche, B., \& Dawson, D. L. (2019). The Acceptance and Action Questionnaire-II (AAQ-II) as a measure of experiential avoidance: Concerns over discriminant validity. Journal of Contextual Behavioral Science, 12, 278-284. https://doi.org/10.1016/j.jcbs.2018.09.005

Tyndall, I., Waldeck, D., Pancani, L., Whelan, R., Roche, B., \& Pereira, A. (2020). Profiles of Psychological Flexibility: A Latent Class Analysis of the Acceptance and Commitment Therapy Model. Behavior Modification, 44(3), 365-393. https://doi. org/10.1177/0145445518820036

Upmane, A. (2012). Apmierinātību ar dzivi prognozējošie faktori: kvantitativa un kvalitatīva analize. Promocijas darbs. Latvijas Universitāte, Rìga.

Zhang, C.-Q., Chung, P.-K., Si, G., \& Liu, J. D. (2014). Psychometric Properties of the Acceptance and Action Questionnaire-II for Chinese College Students and Elite Chinese Athletes. Measurement \& Evaluation in Counseling \& Development, 47(4), 256-270. https:// doi.org/10.1177/0748175614538064

Vowles, K. E., McCracken, L. M., McLeod, C., \& Eccleston, C. (2008). The Chronic Pain Acceptance Questionnaire: Confirmatory factor analysis and identification of patient subgroups. PAIN, 140(2), 284-291. https://doi.org/10.1016/j.pain.2008.08.012

Westin, V., Hayes, S. C., \& Andersson, G. (2008). Is it the sound or your relationship to it? The role of acceptance in predicting tinnitus impact. Behaviour Research and Therapy, 46(12), 1259-1265. https://doi.org/10.1016/j.brat.2008.08.008

Wolgast, M. (2014). What Does the Acceptance and Action Questionnaire (AAQ-II) Really Measure? Behavior Therapy, 45(6), 831-839. https://doi.org/10.1016/ j.beth.2014.07.002 